\title{
Variance Analysis of Intestinal Microbial Diversity of the Noble Scallop (Chlamys nobilis) under Enrofloxacin Exposure
}

\author{
Jiawei Hong ${ }^{1,2}$, Mingqiang Chen ${ }^{1,2}$, Zhenghua Deng ${ }^{1,2}$, Youning $\mathrm{Li}^{1,2}$ and Yu \\ Wang $^{1,2 *}$ \\ ${ }^{1}$ Tropical Aquaculture Research and Development Center, South China Sea Fisheries \\ Research Institute, Chinese Academy of Fishery Sciences, Sanya, 572018, China \\ ${ }^{2}$ Key Laboratory of South China Sea Fishery Resources Exploitation and Utilization, \\ Ministry of Agriculture, Guangzhou, 510300, China
}

Jiawei Hong and Mingqiang Chen contributed equally to this work.

\begin{abstract}
A B S T R A C T
To investigate the possible impact of enrofloxacin (ENR) on noble scallop (Chlamys nobilis), we quantitatively evaluated the microbial shifts in the intestine of noble scallop in response to enrofloxacin treatments at different dosages $(0,5$, and $10 \mathrm{mg} / \mathrm{L}$ ENR) using $16 \mathrm{~S}$ rDNA gene sequencing. A total of 11 phyla comprising 76 genera were detected. At the phylum level, the relative abundance of Proteobacteria increased (from $34.96 \%$ to $77.31 \%$ ) with the increasing of enrofloxacin exposure dosage. The dominant position of Tenericutes was replaced by Proteobacteria, and in parallel the proportion of Tenericutes slumped to $3.85 \%$. At the genus level, the relative abundance of Mycoplasma, dropped down from $58.38 \%$ to $3.85 \%$, and Vibrio increased (from $15.23 \%$ to $40.8 \%$ ) to become the dominant genus. The hierarchical clustering heat map analysis and principal component analysis (PCA) showed that the microbial community of the high dosage group $(10 \mathrm{mg} / \mathrm{L})$ was clearly different from the other two groups. Overall, enrofloxacin at high dosage of $10 \mathrm{mg} / \mathrm{L}$ significantly altered the community diversity of noble scallop. This study characterized the variation regularity of the intestinal microbial of the noble scallop in response to enrofloxacin treatment. These results, provide a comprehensive acquaintance with intestinal microecosystem of the noble scallop and contributes to a reasonable use of enrofloxacin treatment on noble scallop.
\end{abstract}

Article Information
Received 25 April 2019
Revised 23 June 2019
Accepted 06 August 2019
Available online 12 April 2021
Authors' Contribution
JH conceived the idea and wrote
the manuscript. MC and YL helped in
field experimental work. ZD assisted
in data analysis. YW supervised the
manuscript.
Key words
Chlamys nobilis, microbial diversity,
enrofloxacin, 16S rDNA

\section{INTRODUCTION}

$\mathrm{T}$ he intestine is the most important digestive organ, and hosts a large amount of microbes with complex structures. Microbial community is an indispensable part of the host (Pérez et al., 2010; Abid et al., 2013; Cahenzli et al., 2013), which maintains a dynamic balance in the intestine and plays an important role in nutrition metabolism, regulating immune function and resisting pathogens (Macpherson et al., 2004; Sekirov et al., 2010; Martiny et al., 2015). Intestinal microbes help maintain the barrier function of the intestinal mucosal system (Hecht et al., 1999; Cho et al., 2012). In case this balance is destroyed, the host will be more susceptible to various diseases due to the intestinal community disorders (Ring et al., 2003).

\footnotetext{
* Corresponding author: winterrose@163.com 0030-9923/2021/0004-1221 \$ 9.00/0

Copyright 2021 Zoological Society of Pakistan
}

Therefore, maintaining the stability of intestinal microbial community structure is an important factor to avoid the occurrence of bacterial diseases (Round et al., 2009).

The noble scallop Chlamys nobilis Reeve (Pectinidae, Pterioida), widely distributed in Japan, Indonesia and the Southern Sea of China, is cultivated as an important economic mollusk in China (Qiu et al., 2007; Zheng et al., 2010). As invertebrates, shellfish do not have specific immune system to resist the infection of various pathogens that reduce the impact of environmental stress (Anderson, 1988). The normal intestinal community structure and function are particularly important for scallops. Studies on the diversity of microbiota in the intestinal tract have been greatly developed by the high throughput sequencing technology. The method makes great improvement in the depth and breadth of microbial diversity analysis in animals, and allows for an insight into understanding of the structure and function of intestinal microbial community (Turnbaugh et al., 2009; Caporaso et al., 2012; 
Ye et al., 2014; Zhang et al., 2015). Therefore, we want to investigate the intestinal microbial diversity of noble scallop using this technology so that it can give us an another view on this problem.

Because of the non-hygienic and stressful conditions in aquaculture facilities, the risk of bacterial infections is high and leads to frequent use of antibiotics (Sapkota et al., 2008). However, the most common side effect of antibiotics is its impacts on intestinal microecology (Kim et al., 2012). Shifts in the composition of intestinal community induced by the excessive use of antibiotics may cause disorder in the ecological balance between microorganisms and host, and allow for the proliferation of pathogens and cause infection (Kim et al., 2012; Li et al., 2017). Many investigations have been conducted to study the intestinal community of many organisms in recent years (Ley et al., 2006; Han et al., 2010; Chen et al., 2015, 2016, 2018) , such as crap, golden pompano, chicken and human, but few studies about the shifts of intestinal microbial in animals after exposure of mollusks to antimicrobials, have been reported. Enrofloxacin is an efficient broadspectrum antimicrobial against a lot of bacterial diseases (Sarkozy, 2001; Committee for Medicinal Products for Veterinary Use (CVMP), 2007), and it's one of the most used antimicrobials in aquaculture. In the present study, thus, the intestinal microbial diversity of noble scallop was analyzed by high throughput sequencing in response to different dosages of enrofloxacin, with the aim of characterizing their variation regularity, and suggest an appropriate therapeutic regimen for bacterial infections of noble scallop.

\section{MATERIALS AND METHODS}

\section{Animals}

Experimental noble scallops (shell length $71.71 \pm 0.57$ $\mathrm{mm}$, shell height $72.71 \pm 0.51 \mathrm{~mm}$, shell width $24.61 \pm 0.56$ $\mathrm{mm}$, and wet weight $64.65 \pm 1.56 \mathrm{~g}$ ) were collected from a local farm in Xincun Town, Lingshui, China, and transported to Tropical Fisheries Research and Development Center, South China Sea Fisheries Research Institute, Chinese Academy of Fishery Science, temporary reared for two week following the management method described by Handa (2016).

\section{Experiment design and sample collection}

The enrofloxacin crystal was dissolved in 3 fiberglass tanks with $400 \mathrm{~L}$ volume equipped with sand filtered seawater. The concentrations of enrofloxacin in each group were determined according to the HPLC (highperformance liquid chromatography) method proposed by Fang et al. (2012). The following three treatments (including the control) were used: $0 \mathrm{mg} / \mathrm{L} \mathrm{ENR,} 5 \mathrm{mg} / \mathrm{L}$ ENR, $10 \mathrm{mg} / \mathrm{L}$ ENR. Animals were deprived food during the experimental period, and the experiment lasted for $24 \mathrm{~h}$. After 24 hours immersion, three scallops were randomly collected from each tank and marked as follows: $0 \mathrm{mg} / \mathrm{L}$ group (CA group includes: CA1, CA2, CA3), $5 \mathrm{mg} / \mathrm{L}$ group (CB group includes: CB1, CB2, CB3), and $10 \mathrm{mg} / \mathrm{L}$ group (CC group includes: $\mathrm{CC} 1, \mathrm{CC} 2, \mathrm{CC} 3$ ). The intestine was removed with scissors and tweezers sterilized by alcohol lamp and rinsed with sterile $0.85 \%(w / v)$ saline solution. Samples were immersed in $75 \%$ ethanol for $3 \mathrm{~min}$ and then rinsed sterile saline solution for 3 times. The intestinal contents were put in $1.5 \mathrm{~mL}$ sterile freezing tubes, and were immediately transferred to store at $-80{ }^{\circ} \mathrm{C}$ for later DNA extraction.

\section{DNA extraction}

The total DNA was extracted from the intestinal contents using the E.Z.N.A DNA Kit (Omega Bio-Tek, Norcross, GA, USA) according to the manufacturer's protocol. Qubit 3.0 fluorescent photometer and agarose gel electrophoresis were used to detect the content and quality of DNA.

\section{PCR amplification and $16 \mathrm{~S}$ rDNA library construction}

The V3-V4 hypervariable region of bacterial 16S rDNA gene was amplified by PCR using the specific primer (forward primer: 5'CCTACGGRRBGCASCAGKVRVGAAT-3', reverse primer: 5'-GGACTACNVGGGTWTCTAATCC-3') designed by Illumina MiSeq platform. Sequencing adapters were added to the terminal of PCR products to facilitate the later Miseq sequencing. All PCR amplifications were performed in triplicate at $25 \mu \mathrm{L}$ reactions mixture containing: $2.5 \mu \mathrm{L}$ of TransStart buffer, $2 \mu \mathrm{L}$ of dNTPs mixture, $1 \mu \mathrm{L}$ of each primer, $20 \mathrm{ng}$ of template DNA. The thermal cycling program was performed as follows: initial denaturation at $94^{\circ} \mathrm{C}$ for $3 \mathrm{~min}, 24$ cycles of denaturation at $94^{\circ} \mathrm{C}$ for $5 \mathrm{~s}$, annealing at $57^{\circ} \mathrm{C}$ for $90 \mathrm{~s}$, extension at $72^{\circ} \mathrm{C}$ for $10 \mathrm{~s}$, and a final extension at $72^{\circ} \mathrm{C}$ for $5 \mathrm{~min}$. The quality of amplified PCR products was checked by electrophoresis in $1.5 \%(w / v)$ agarose gel, then separated and purified with the Quick Gel Extraction Kit (Qiagen, Hilden, Germany). Purified PCR products were used for gene library construction and high-throughput sequencing.

\section{Bioinformatics analysis}

The concentration of DNA library was detected by Qubit 3.0 fluorescent photometer, The DNA library was quantified to $10 \mathrm{nM}$ and then loaded samples to Illumina MiSeq device (Illumina, San Diego, CA, USA) for sequencing according to the instruction. PE 250/300 
were used for pairing with ends, picture analysis and base check were performed by the MiSeq control software (MCS) attached to the MiSeq device. Paired-end reads were assigned to samples based on their unique barcode and truncated by cutting off the barcode and primer sequence (Schloss et al., 2009). Pyrosequencing reads with ambiguous bases, quality score of $\mathrm{Q} \geq 20$, and reads shorter than 200 bp were removed. Raw data were merged using Flash (version v1.2.7) and filtered by Qiime (version v1.9.1). Uchime analysis was then performed to remove chimeric clusters from the sequencing data from each sample (Caporaso et al., 2012). Effective data were clustered at a $97 \%$ sequence identity into operational taxonomic units (OTUs) using Uparse (version v7.0.1001) software, and taxonomic OTU assignments were accomplished by Ribosomal Database Project (RDP) Classifer (Caporaso et al., 2010). Representative sequences of OTUs were aligned using the Silva_128 16S rRNA database (Koetschan et al., 2014). Rarefaction curves were analyzed with Mothur (version v.1.30). Qiime was used to calculate the bacterial alpha diversity index, including Shannon and Simpson (diversity), abundancebased coverage estimator (Ace) and Chaol (richness), and coverage (the Good's coverage ). Beta diversity was used as a comparative analysis of microbial communities in different samples. Heatmaps were generated with the $\mathrm{R}$ package (Kang et al., 2013). UniFrac PCA was used for the principal component analysis (PCA).

\section{Statistical analysis}

Data were analyzed using the SPSS 19.0 statistical software packages. All values are presented as the means \pm standard deviation (mean $\pm \mathrm{SD}$ ). The data were determined by use of one-way analysis of variance (ANOVA). The statistical significance was accepted at $P<0.05$.

\section{RESULTS}

\section{Microbial community richness and diversity}

A total of 946,800 effective sequences were obtained from the total nine samples after processing with the number of sequences ranging from 46,421 to 124,102 per sample. The average length of effective sequences was 460.39 (Table I). The sequences were clustered into 273 OTUs (Operational Taxonomic Units) at the 97\% similarity level, and the number of OTUs for each group was 233, 228, 199, respectively. The rarefaction curves tended to approach a saturation plateau with the increase of sequencing depth (Fig. 1), which indicated that the obtained sequences could commendably represent the entire microbial community in the present study. The Good's coverage of the three groups (Table II) was about
$100 \%$, which also reflected the reliability of the results.

Table I. Statistics of sequences.

\begin{tabular}{lll}
\hline Sample ID & Effective sequences & Average length (bp) \\
\hline CA1 & 107210 & 455.01 \\
CA2 & 115886 & 461.29 \\
CA3 & 114061 & 460.94 \\
CB1 & 124102 & 458.30 \\
CB2 & 110516 & 462.10 \\
CB3 & 46421 & 461.54 \\
CC1 & 111091 & 462.13 \\
CC2 & 108051 & 462.14 \\
CC3 & 109462 & 460.02 \\
Mean & 105200 & 460.39 \\
\hline
\end{tabular}

Table II. Microbial community richness and diversity indices of each treatment.

\begin{tabular}{lccc}
\hline \multicolumn{3}{c}{ Treatment } \\
\hline \multicolumn{1}{c}{ CA } & \multicolumn{1}{c}{ CB } & \multicolumn{1}{c}{ CC } \\
\hline ACE & $173.05 \pm 34.91^{\mathrm{a}}$ & $169.72 \pm 10.32^{\mathrm{a}}$ & $131.15 \pm 43.89^{\mathrm{a}}$ \\
Chao1 & $176.76 \pm 38.01^{\mathrm{a}}$ & $171.79 \pm 12.65^{\mathrm{a}}$ & $130.53 \pm 43.66^{\mathrm{a}}$ \\
Simpson & $4.00 \pm 0.32^{\mathrm{a}}$ & $4.15 \pm 0.6^{5} \mathrm{a}$ & $4.37 \pm 0.75^{\mathrm{a}}$ \\
Shannon & $0.85 \pm 0.04^{\mathrm{a}}$ & $0.88 \pm 0.05^{\mathrm{a}}$ & $0.91 \pm 0.04^{\mathrm{a}}$ \\
$\begin{array}{l}\text { Good's } \\
\text { coverage }\end{array}$ & $1.0 \pm 0.0^{\mathrm{a}}$ & $1.0 \pm 0.0^{\mathrm{a}}$ & $1.0 \pm 0.0^{\mathrm{a}}$ \\
\hline
\end{tabular}

In the same row, values with different letter superscripts mean significant differences $(\mathrm{P}<0.05)$. ACE and Chao 1 are used to calculate the community richness and estimate the number of OTUs in community. Simpson and Shannon are used to estimate the community diversity. Good's Coverage is the coverage of the sample libraries. The higher the coverage, the lower the probability that the sequences in the sample are not detected.

Table II presented the alpha diversity of three exposure groups. The community richness was estimated based on the alpha-diversity indices (Chao 1, and ACE index), a higher number of which represents more richness. The ACE and Chao 1 indices of three groups were173.05 $\pm 34.91,169.72$ $\pm 10.32,131.15 \pm 43.89$ and $176.76 \pm 38.01,171.79 \pm 12.65$, $130.53 \pm 43.66$, respectively. In addition, the microbial community diversity was demonstrated by alpha-diversity estimations (Shannon and Simpson indexes). The higher Shannon index or the lower Simpson index means higher diversity of microbial community in the sample. The Simpson and Shannon indices of three groups were $4.00 \pm 0.32,4.15$ $\pm 0.65,4.37 \pm 0.75$ and $0.85 \pm 0.04,0.88 \pm 0.05,0.91 \pm 0.04$, respectively. Microbial community richness and diversity had 
no significant difference among three groups $(P>0.05)$.

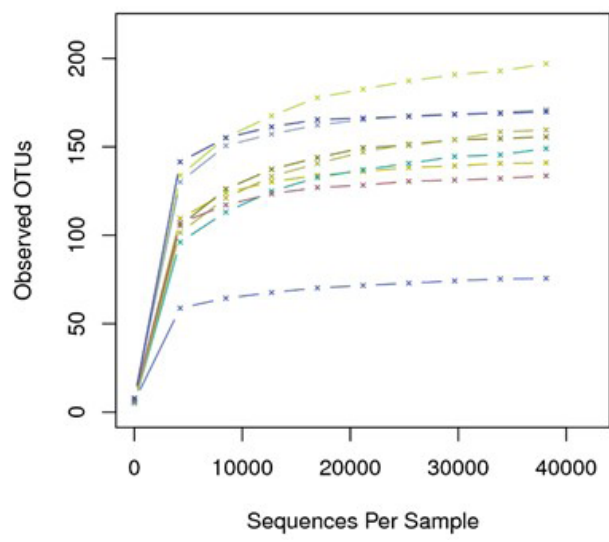

Fig. 1. Rarefaction curves of the OUTs for nine samples. Sequences were clustered at $97 \%$ sequence similarity.

To evaluate the distribution of OTUs among the different samples, the Venn diagram was made (Fig. 2), which described the shared OTUs and unique OTUs. The shared OTUs indicated the microbial community similarity, while the unique OTUs showed the microbial community difference among the samples. 40 OTUs were shared by $\mathrm{CA}$ and $\mathrm{CB}$ group, and only 8 OTUs were shared by $\mathrm{CB}$ and $\mathrm{CC}$ group. Accordingly, OTUs shared by $\mathrm{CC}$ and CA group decreased to 13 . The decreasing shared OTUs indicated that the microbial community structure changed when the concentration of enrofloxacin up to $10 \mathrm{mg} / \mathrm{L}$.

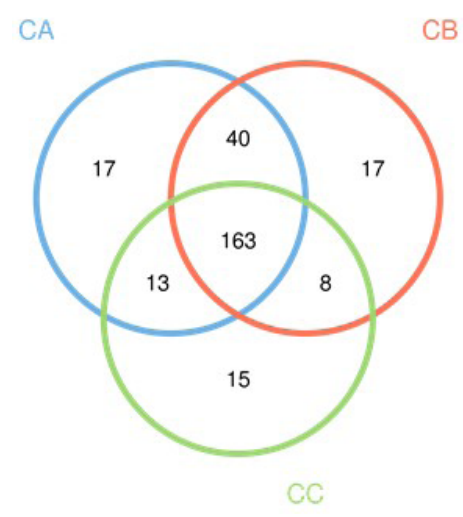

Fig. 2. OTUs distribution in community level in venn diagram.

\section{Microbial community composition and structure}

A total of 11 phyla comprising 76 genera were identified by the RDP classifier. The relative abundances of bacterial community at the phylum level are illustrated in Figure 3a. After data standardization, the relative abundance from high to low was Proteobacteria, Tenericutes, Firmicutes, Cyanobacteria, Bacteroidetes, Spirochaetae, Fusobacteria, Deinococcus-Thermus, one unclassified phylum, Actinobacteria, Gracilibacteria. In details, Proteobacteria, Tenericutes, Firmicutes, Cyanobacteria, Bacteroidetes were the five dominant phyla which, in total, accounted for $98.64 \%, 99.66 \%$, and $99.38 \%$ of the entire microbial community respectively. The relative abundance of Proteobacteria increased gradually from $34.96 \%$ to $77.31 \%$ with the increased enrofloxacin concentration. As a result, the most abundant division changed from Tenericutes to Proteobacteria, and the proportion of Tenericutes decreased gradually at the same time. Cyanobacteria had the same trend with Tenericutes, while Firmicutes rose obviously until the concentration reached $10 \mathrm{mg} / \mathrm{L}$.

Figure $3 \mathrm{~b}$ showed the top thirty most abundant genera at the genus level under different enrofloxacin concentrations and other genera were grouped as the "others". Vibrio, Mycoplasma, Exiguobacterium, Nannochloropsis-oceanica, Citrobacter, EscherichiaShigella, Photobacterium, Acinetobacter, Amphritea and an unclassified genus were the dominant genera, which collectively represented about 92.68\%, 92.1\%, 84.15\% of the microbial community respectively. There were some changes of the top ten dominant genera between the total microbe populations under different enrofloxacin concentrations. The control group $(0 \mathrm{mg} / \mathrm{L})$ contained highest proportion of Mycoplasma (58.38\%), which fell sharply to $3.85 \%$ at the high enrofloxacin concentration $(10 \mathrm{mg} / \mathrm{L})$. With the increased enrofloxacin concentrations, Mycoplasma lost the leading position and was replaced by Vibrio (the relative abundance increased from $15.23 \%$ to $40.8 \%$ ). Exiguobacterium, Citrobacter, EscherichiaShigella, and Acinetobacter had a similar trend as Vibrio.

\section{Similarities in microbial community structure}

A hierarchical clustering heat map analysis was performed at the genus level based on the top 30 most abundant microbial communities across three groups (Fig. 4). The analysis displayed that the samples were segregated into two groups. One group was composed of first two enrofloxacin treatments $\mathrm{CA}$ and $\mathrm{CB}$, and $\mathrm{CC}$ were assigned to the other group independently. In addition, the principal component analysis also showed a similar trend as in the hierarchical clustering heat map analysis (Fig. 5). The principal component analysis (PCA) indicated that the bacteria community in $\mathrm{CA}$ and $\mathrm{CB}$ that clustered together had a greater difference than in $\mathrm{CC}$. They were also distinctly different than in PC2 than in PC1. 


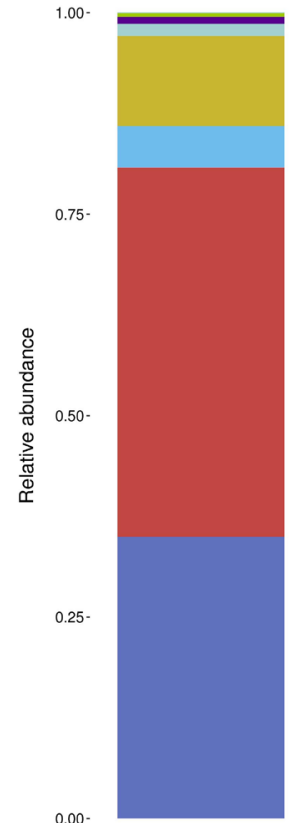

A

ذ̇

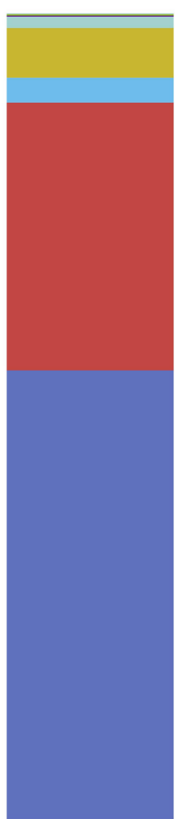

$\dot{8}$

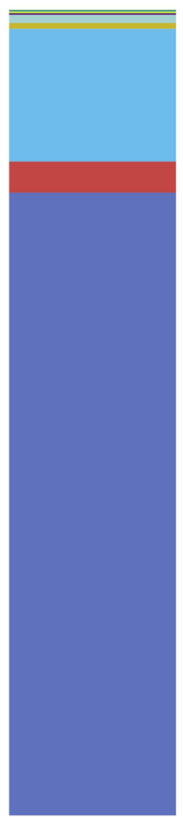

ن

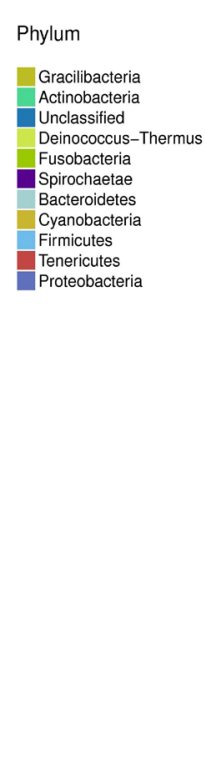

B
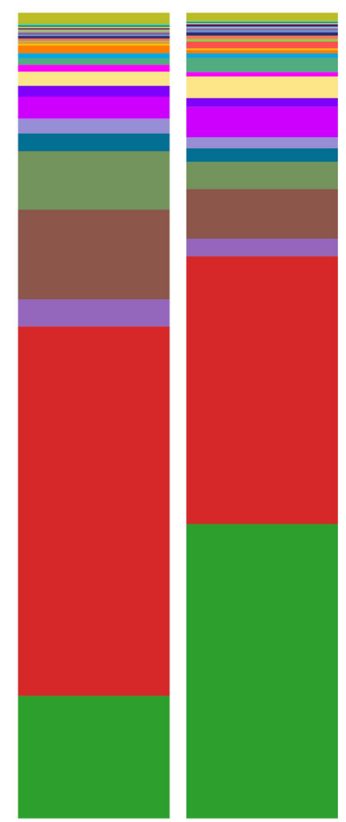

ஷ்

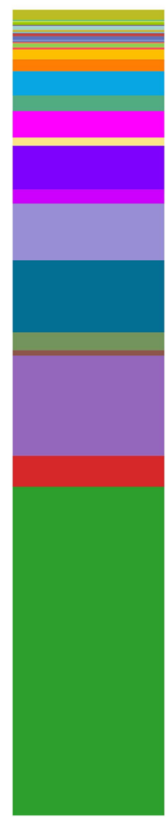

Genus

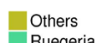

RD1-7_clade

Borrelia

Chryseobacteriu

Shewanella

Candidatus_Endoecteinascidia

Bacilus

Neptuniibacter

Enterococcus

Thalassotale

Prolixibacter

Tenacibaculum

Alteromonas

Psychrobium

Lactococcus

Anoxybacillus

Arcobacter

Pseudoalteromentomas
Pseudomonas

Amphritea

Acinetobacter

Photobacterium

Escherichia-Sh
Citrobacter

Unclassified
Nannochloropsis_oceanica

Nannochloropsis

Mycoplasma

Mycoplasma
Vibrio

Fig. 3. Relative abundance of microbial phyla (A) and relative abundance of microbial genera (B).

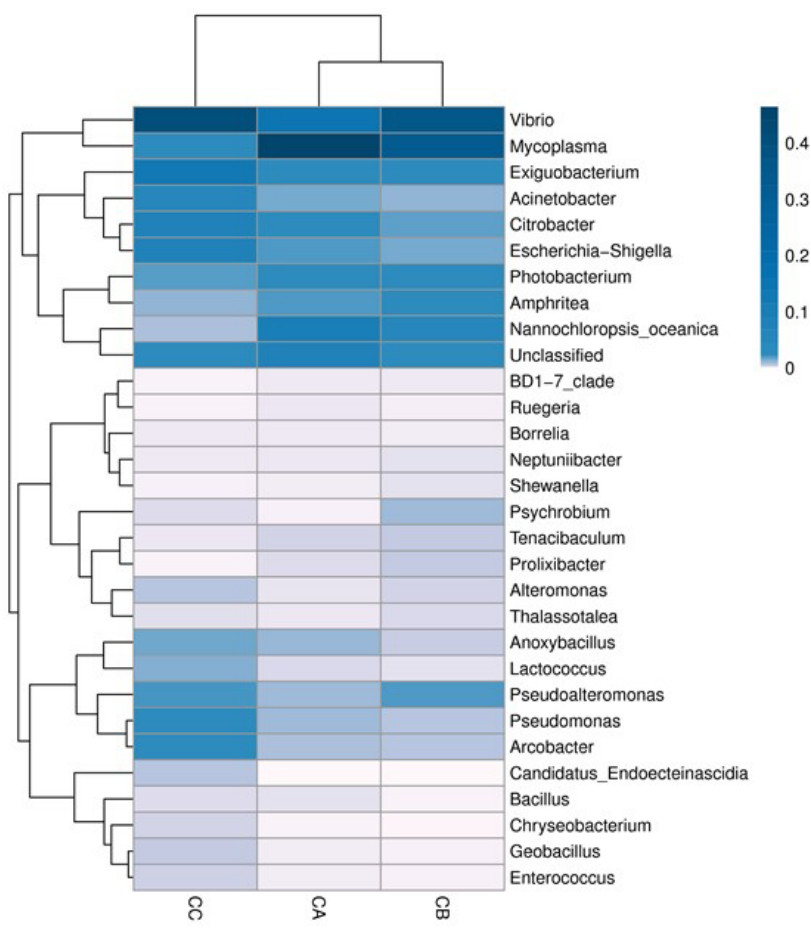

Fig. 4. The hierarchical clustering heat map analysis of the genera.

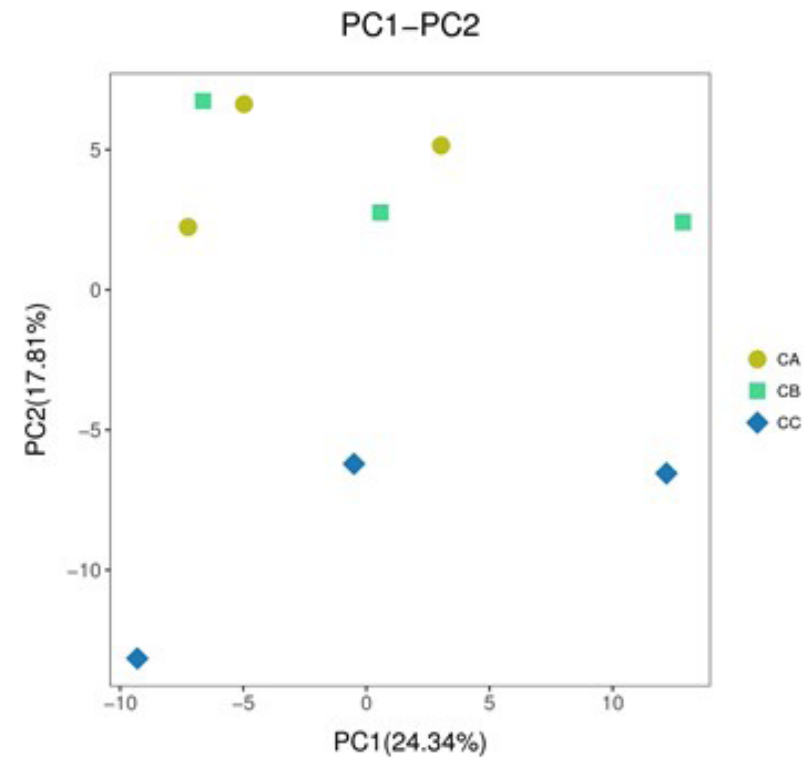

Fig. 5. Principal component analysis (PCA) of community structures.

\section{DISCUSSION}

The intestinal tract of animals hosts complex and diverse microfloras, which collectively form an important functional unit and play an important role on the growing 
development of the host. Therefore, the stability of intestinal flora is of great significance for the healthy growth of the host (Ley et al., 2008; Nayak, 2010; Suez et al., 2014). When the species, amount and proportion of normal intestinal flora change abnormally, which deviate from the normal balance state, and translate into a pathological combination, that causes flora dysbiosis (Ley et al., 2005; Ley et al., 2006). At present, improper use of antibiotics has become the most common inducement of intestinal flora dysbiosis (Nord, 1990). Thus, we investigated the detailed impact of antibiotic, enrofloxacin in particular, on the intestinal microbial community of noble scallop using 16S rDNA gene sequencing.

Through sequencing results, we found that the microbial community at the phylum level was predominated by Proteobacteria and Tenericutes, which made up 34.96\% and $45.86 \%$ of the control group respectively. The result was in accordance with the previous studies. Tanaka et al. (2004) and Nel et al. (2017) studied on the intestinal microbial community of cultured Haliotis discus hannai and Haliotis midae, as well as investigations on bivalves by other authors (Winters et al., 2011; Cleary et al., 2015; Rubiolo et al., 2018) also showed the same results. Not only bivalves, but also some fish have been studied to characterize as dominated by Proteobacteria and Tenericutes, such as rainbow trout (Oncorhynchus mykiss) (Wong et al., 2013). However, the result showed some differences with study on crustacean Litopenaeus vannamei, Fusobacteria and Actinobacteria also account for a large percentage except Proteobacteria and Tenericutes (Zhang et al., 2014). Futhermore, compared with different groups, the relative abundance of Proteobacteria increased with the increased enrofloxacin exposure dosage so that the dominant position of Tenericutes has replaced by Proteobacteria. Tenericutes are a distinctive class of bacteria that lack a cell wall, which can be pathogenic to humans (Razin et al., 1998). In aquatic animals, Rubiolo et al. (2018) suggests a tight association of Tenericutes to mussel hepatopancreass. While the role of these bacteria is still unclear, since they have been implied in pathogenesis of pacific white shrimp (Krol et al., 1991) and cockle (Azevedo, 1993). Thus, Tenericutes had a potential perniciousness to animals' health according to the described above. The decrease of Tenericutes in this study indicated that Tenericutes may be sensitive to enrofloxacin, we can use enrofloxacin to control the Tenericutes community according to this and decline the possible pathogenic risk.

On the other hand, Proteobacteria is the most unstable among the four main phyla (Firmicutes, Bacteroidetes, Proteobacteria, and Actinobacteria) in the intestinal microbiota (Faith et al., 2013). The selective pressure driven by dysbiosis can influence the stability of the microbial community and impair resistance to colonization, then Proteobacteria subsequently take the opportunity to make an expansion. Accordingly, an increased prevalence of Proteobacteria can be a marker for an unstable microbial community and a potential diagnostic criterion for disease (Shin et al., 2015). As previous studies illustrated, the expansion of intestinal Proteobacteria, at a deep level, reflects disturbances in metabolic and the innate immune response (Carvalho et al., 2012; Fei and Zhao, 2013). Therefore, our result suggests that the relative abundance of Proteobacteria increased after enrofloxacin treatment are evidence of an unstable microbial community of noble scallop, which will place the noble scallop in possible danger of affecting its physiological metabolic and making invasion by exogenous pathogens.

At the genus level, the most highly represented genus was Mycoplasma, which accounted for more than 50\% of total detected OUTs. Mycoplasma is the smallest and simplest prokaryote so far has been found. It can infect people and other mammals and cause pneumonia and other diseases, such as well-known pathogens, Mycoplasma pneumonia and M. gallisepticum (Aceves et al., 2018). In some cases, they become intracellular pathogens, but under appropriate environmental conditions most remain a benign member of the host's microbiome (Brown et al., 2005). Although Mycoplasma was often reported to be pathogenic, it should play a positive role on noble scallop because it's abundant in intestine of ordinary individuals. Thus, its specific function to noble scallop needs further studies.

Our study also revealed that, with the increased enrofloxacin concentrations, the relative abundance of Mycoplasma dropped down and made space for Vibrio. Vibrio is the main genera of Proteobacteria. It was also detected on penaeid shrimp (Dempsey et al., 1989) and yellow catfish (Wu et al., 2010). Interestingly, Vibrio, which often acts as pathogen, increased obviously under the enrofloxacin treatment. The result is different from that done by Dethlefsen et al. (2008). Dethlefsen infected the body with Vibrio in advance, so the difference is likely due to the discrepant initial amount of Vibrio. Also, Vibrio is one of the most common opportunistic pathogens in marine environment and organisms. Its pathogenicity is greatly influenced by the physiological state of host and ambient water quality (Flick, 2007). In gram-negative bacteria, Vibrio has extremely powerful capacity of secreting extracellular protein (enzyme) (Marcello et al., 1996). The combine of extracellular enzyme products and hemolytic factors can destroy the cell membrane, mitochondria, endoplasmic reticulum and other cell endomembrane system in the body, resulting in the metabolic disorders of material and energy (Ghannoum et al., 2000). 
Enrofloxacin have an action on bacterial topoisomerase as consequence of inhibiting DNA replication. It is reported a broad-spectrum antimicrobial, which is efficient on most gram-negative and gram-positive bacteria including Vibrio (Wang et al., 2005; Yu et al., 2014; Trouchon and Lefebvre, 2016), but on the contrary, it brought excessive growth of Vibrio as showed above. Given that Vibrio has such high pathogenicity, we should pay more attention to the boom of Vibrio after the use of enrofloxacin according to this study, and choose the better dosage of enrofloxacin to avoid the possible adverse effects behind.

At last, similarities in entire microbial community structure between groups were given by principal component analysis (PCA) and the hierarchical clustering heat map analysis. In PCA, PC1 and PC2 explained 42.15\% of the variation of microbial community composition in total. the analysis supported that control group and low enrofloxacin dosage group were clustered together and clearly separated from the high enrofloxacin dosage group. The hierarchical clustering heat map analysis had the same result with principal component analysis. These results indicated that the high dosage of enrofloxacin (10 $\mathrm{mg} / \mathrm{L}$ ) had significant impact on the intestinal microbial community structure of noble scallops.

\section{CONCLUSION}

In summary, $10 \mathrm{mg} / \mathrm{L}$ enrofloxacin significantly affected the intestinal microbial community structure of noble scallop, which may bring potential dangerous to host health. Therefore, the low concentration of enrofloxacin $(5 \mathrm{mg} / \mathrm{L})$ can be used as a safe dosage for noble scallop treatment without causing adverse effects to its intestinal flora structure. Our research provides initial guidance for the use of enrofloxacin in noble scallop, and helps to formulate appropriate treatment plans with taking the impact on intestinal flora into account. Finally, we hope to make contribution to eliminate or reduce flora disorders caused by the abuse of antibiotics and the spread of drugresistant strains.

\section{ACKNOWLEDGEMENTS}

This research was financially supported by Hainan Provincial Key Research and Development Project (ZDYF2016079, ZDYF2016086).

\section{Statement of conflict of interest}

Authors have declared no conflict of interest.

\section{REFERENCES}

Abid, A., Davies, S.J., Waines, P., Emery, M., Castex, M., Gioacchini, G., Carnevali, O., Bickerdike, R., Romero, J. and Merrifield, D.L., 2013. Dietary synbiotic application modulates atlantic salmon (Salmo salar) intestinal microbial communities and intestinal immunity. Fish Shellf. Immunol., 35: $\quad 1948-1956 . \quad$ https://doi.org/10.1016/j. fsi.2013.09.039

Aceves, A.K., Johnson, P., Bullard, S.A., Lafrentz, S. and Arias, C.R. 2018. Description and characterization of the digestive gland microbiome in the freshwater mussel Villosa nebulosa (Bivalvia: Unionidae). J. Mollus. Stud., 84: 240-246. https://doi.org/10.1093/ mollus/eyy014

Anderson, R.S., 1988. Effects of anthropogenic agents on bivalve cellular and humoral defense mechanisms. Disease processes in marine bivalve mollusk. Special publication No.18. American Fisheries Society, Bethesda, USA.

Azevedo, C., 1993. Occurrence of an unusual branchial mycoplasma-like infection in cockle Cerastoderma edule (Mollusca, Bivalvia). Dis. Aquat. Organ., 16: 55-59. https://doi.org/10.3354/dao016055

Benson, A.K., Kelly, S.A., Legge, R., Ma, F., Low, S.J., Kim, J., Zhang, M., Oh, P.L., Nehrenberg, D., Hua, K., Kachman, S.D., Moriyama, E.N., Walter, J., Peterson, D.A. and Pomp, D., 2010. Individuality in gut microbiota composition is a complex polygenic trait shaped by multiple environmental and host genetic factors. Proc. natl. Acad. Sci. USA., 107: 18933. https://doi.org/10.1073/pnas.1007028107

Booman, M., Forster, I., Vederas, J.C., Groman, D.B., Jones, S.R., 2018. Soybean meal-induced enteritis in Atlantic salmon (Salmo salar) and Chinook salmon (Oncorhynchus tshawytscha) but not in pink salmon (O. gorbuscha). Aquaculture, 483: 238-243. https://doi.org/10.1016/j.aquaculture.2017.10.025

Brown, D.R., Zacher, L.A., Wendland, L.D. and Brown, M.B., 2005. Emerging mycoplasmoses in wildlife. In: Mycoplasmas: Molecular biology pathogenicity and strategies for control (eds. A. Blanchard and G. Browning), Horizon Bioscience, Wymondham, Norfolk, UK, pp. 383-414.

Cahenzli, J., Köller, Y., Wyss, M., Geuking, M.B. and McCoy, K.D., 2013. Intestinal microbial diversity during early-life colonization shapes long-term ige levels. Cell Host Microbe, 14: 559-570. https://doi. org/10.1016/j.chom.2013.10.004

Cai, W., Li, Y., Niu, L., Zhang, W., Wang, C., Wang, P. and Meng, F., 2017. New insights into the spatial 
variability of biofilm communities and potentially negative bacterial groups in hydraulic concrete structures. Water Res., 123: 495-504. https://doi. org/10.1016/j.watres.2017.06.055

Caporaso, J.G., Kuczynski, J., Stombaugh, J., Bittinger, K., Bushman, F.D., Costello, E.K., Fierer, N., Peña, A.G., Goodrich, J.K., Gordon, J.I., Huttley, G.A., Kelley, S.T., Knights, D., Koenig, J.E., Ley, R.E., Lozupone, C.A., Mcdonald, D., Muegge, B.D., Pirrung, M., Reeder, J., Sevinsky, J.R., Turnbaugh, P.J., Walters, W.A., Widmann, J., Yatsunenko, T., Zaneveld, J. and Knight, R., 2010. QIIME allows analysis of high-throughput community sequencing data. Nat. Methods, 7: 335-336. https://doi. org/10.1038/nmeth.f.303

Caporaso, J.G., Lauber, C.L., Walters, W.A., BergLyons, D., Huntley, J., Fierer, N., Owens, S.M., Betley, J., Fraser, L., Bauer, M., Gormley, N., Gilbert, J.A., Smith, G. and Knight R. 2012. Ultrahigh-throughput microbial community analysis on the Illumina HiSeq and MiSeq platforms. ISME J., 6: 1621. https://doi.org/10.1038/ismej.2012.8

Carvalho, F.A., Koren, O., Goodrich, J.K., Johansson, M.E.V., Nalbantoglu, I. Aitken, J.D., Su, Y.J., Chassaing, B., Walters, W.A., González, A., Clemente, J.C., Cullender, T.C., Barnich, N., Michaud, A. D., Kumar, M.V., Knight, R., Ley, R.E. and Gewirtz, A.T., 2012. Transient inability to manage Proteobacteria promotes chronic gut inflammation in TLR5-deficient mice. Cell Host Microbe, 12: 139-152. https://doi.org/10.1016/j. chom.2012.07.004

Chen, B., Gao, L.L. and Pan, Q., 2018. Woody forages effect the intestinal bacteria diversity of golden pompano Trachinotus ovatus. Amb. Express, 8: 29. https://doi.org/10.1186/s13568-018-0550-2

Chen, X., Di, P., Wang, H., Li, B., Pan, Y., Yan, S. and Wang, Y.J., 2015. Bacterial community associated with the intestinal tract of chinese mitten crab (Eriocheir sinensis) farmed in Lake Tai, China. PLoS One, 10: e0123990. https://doi.org/10.1371/ journal.pone.0123990

Chen, Y., Sun, J., Liao, X.P., Shao, Y., Li, L., Fang, L.X., Liu, Y.H. 2016. Impact of enrofloxacin and florfenicol therapy on the spread of OQXAB gene and intestinal microbiota in chickens. Vet. Microbiol., 192: 1. https://doi.org/10.1016/j.vetmic.2016.05.014

Cho, I. and Blaser, M.J. 2012. The human microbiome: at the interface of health and disease. Nat. Rev. Genet., 13: 260-70. https://doi.org/10.1038/nrg3182

Cleary, D.F.R., Becking, L.E., Polónia, A.R.M., Freitas, R.M. and Gomes, N.C.M., 2015. Composition and predicted functional ecology of mussel-associated bacteria in Indonesian marine lakes. Antonie Von Leeuwenhoek, 107: 821-834. https://doi. org/10.1007/s10482-014-0375-1

Committee for Medicinal Products for Veterinary Use (CVMP). 2007. Public statement on the use of (Fluoro) quinolones in food-producing animals in the European Union: Development of resistance and impact on human and animal health.

Degnan, P.H. and Ochman, H., 2012. Illumina-based analysis of microbial community diversity. ISME J., 6: 183. https://doi.org/10.1038/ismej.2011.74

Dempsey, A.C., Kitting, C.L. and Rosson, R.A., 1989. Bacterial variability among individual penaeid shrimp digestive tracts. Crustaceana, 56: 267-278. https://doi.org/10.1163/156854089X00248

Dethlefsen, L., Huse, S., Sogin, M.L., Relman, D.A., 2008. The pervasive effects of an antibiotic on the human gut microbiota, as revealed by deep $16 \mathrm{~S}$ rRNA sequencing. PLoS Biol., 6: e280. https://doi. org/10.1371/journal.pbio.0060280

Faith, J.J. Guruge, J.L., Charbonneau, M., Subramanian, S., Seedorf, H., Goodman, A.L., Clemente, J.C., Knight, R., Heath, A.C., Leibel, R.L., Rosenbaum, M. and Gordon, J.I., 2013. The long-term stability of the human gut microbiota. Science, 341: 1237439. https://doi.org/10.1126/science.1237439

Fang, X., Liu, X., Liu, W. and Lu, C., 2012. Pharmacokinetics of enrofloxacin in allogynogenetic silver crucian carp, Carassius auratus gibelio. J. Vet. Pharmacol. Ther., 35: 397-401. https://doi. org/10.1111/j.1365-2885.2011.01337.x

Fei, N. and Zhao, L., 2013. An opportunistic pathogen isolated from the gut of an obese human causes obesity in germfree mice. ISME J., 7: 880-884. https://doi.org/10.1038/ismej.2012.153

Flick, J. and G.J., 2007. Pathogenic vibrios in shellfish. Global Aquacul. Advoc., 10: 46-48.

Ghannoum, M.A., 2000. Potential role of phospholipases in virulence and fungal pathogenesis. Clin. Microbiol. Rev., 13: 122-143. https://doi. org/10.1128/CMR.13.1.122

Han, S., Liu, Y., Zhou, Z., He, S., Cao, Y., Shi, P., Yao, B. and Ring, E., 2010. Analysis of bacterial diversity in the intestine of grass carp (Ctenopharyngodon idellus) based on 16s rDNA gene sequences. Aquacul. Res., 42: 47-56. https://doi.org/10.1111/ j.1365-2109.2010.02543.x

Handa, T. and Yamamoto, K.I., 2016. Estimation of CO2 partial pressure and bicarbonate concentration in the hemolymph of the noble scallop. Mimachlamys nobilis. J. Nat. Fish Univ., 64: 188-194. 
Hecht, G., 1999. Innate mechanisms of epithelial host defense: spotlight on intestine. Am. J. Physiol., 277: 351-358. https://doi.org/10.1152/ ajpcell.1999.277.3.C351

Jiang, Y., Wei, L., Yang, K., Shi, X. and Wang, H., 2017. Rapid formation of aniline-degrading aerobic granular sludge and investigation of its microbial community succession. J. Clean. Prod., 166: 1235 1243. https://doi.org/10.1016/j.jclepro.2017.08.134

Kang, X., Liu, G., Liu, Y., Xu, Q., Zhang, M. and Fang, M., 2013. Transcriptome profile at different physiological stages reveals potential mode for curly fleece in chinese tan sheep. PLoS One, 8: e71763. https://doi.org/10.1371/journal.pone.0071763

Kim, B.S., Kim, J.N., Yoon, S.H., Chun, J. and Cerniglia, C.E., 2012. Impact of enrofloxacin on the human intestinal microbiota revealed by comparative molecular analysis. Anaerobe, 18: 310-320. https:// doi.org/10.1016/j.anaerobe.2012.01.003

Kim, H.B., Sreevatsan and Isaacson, R.E., 2012. Microbial shifts in the swine distal gut in response to the treatment with antimicrobial growth promoter, tylosin. Proc. natl. Acad. Sci. USA, 109: 15485. https://doi.org/10.1073/pnas.1205147109

Koetschan, C., Kittelmann, S., Lu, J., Alhalbouni, D., Jarvis, G.N., Müller, T., Wolf, M. and Janssen, P.H., 2014. Internal transcribed spacer 1 secondary structure analysis reveals a common core throughout the anaerobic fungi (Neocallimastigomycota). PLoS One, 9: e91928. https://doi.org/10.1371/journal. pone.0091928

Krol, R.M., Hawkins, W.E. and Overstreet, R.M., 1991. Rickettsial and mollicute infections in hepatopancreatic cells of cultured Pacific white shrimp (Penaeus vannamei). J. Inverteb. Pathol., 57: $\quad 362-370 . \quad$ https://doi.org/10.1016/00222011(91)90140-L

Ley, R.E., Lozupone, C.A., Hamady, M., Knight, R. and Gordon, J.I., 2008. Worlds within worlds: evolution of the vertebrate gut microbiota. Nat. Rev. Microbiol., 6: 776-788. https://doi.org/10.1038/nrmicro1978

Ley, R.E., Peterson, D.A. and Gordon, J.I., 2006. Ecological and evolutionary forces shaping microbial diversity in the human intestine. Cell, 124: 837-848. https://doi.org/10.1016/j.cell.2006.02.017

Ley, R.E., Bäckhed, F., Turnbaugh, P., Lozupone, C.A., Knight, R.D. and Gordon, J.I., 2005. Obesity alters gut microbial ecology. Proc. natl. Acad. Sci. U.S.A. 102: 11070-11075. https://doi.org/10.1073/ pnas.0504978102

Ley, R.E., Turnbaugh, P.J., Klein, S. and Gordon, J.I., 2006. Microbial ecology: human gut microbes associated with obesity. Nature, 444: 1022-1023. https://doi.org/10.1038/4441022a

Li, J., Hao, H., Cheng, G., Liu, C., Ahmed, S., Shabbir, M.A.B., Hussain, H.I., Dai, M.H. and Yuan, Z.H., 2017. Microbial shifts in the intestinal microbiota of salmonella infected chickens in response to enrofloxacin. Front. Microbiol., 8: 1711. https://doi. org/10.3389/fmicb.2017.01711

Macpherson, A.J. and Harris, N.L., 2004. Interactions between commensal intestinal bacteria and the immune system. Nat. Rev. Immunol., 4: 478-485. https://doi.org/10.1038/nri1373

Marcello, A., Loregian, A., De Filippis, V., Fontana, A., Hirst, T.R. and Palù, G., 1996. Identification and characterization of an extracellular protease activity produced by the marine vibrio sp 60 . FEMS Microbiol. Lett., 136: 39-44. https://doi. org/10.1111/j.1574-6968.1996.tb08022.x

Martiny, J.B., Jones, S.E., Lennon, J.T. and Martiny, A.C., 2015. Microbiomes in light of traits: a phylogenetic perspective. Science, 350: aac9323. https://doi. org/10.1126/science.aac9323

Meng, H., Zhang, Y., Zhao, L., Zhao, W., He, C., Honaker, C.F., Zhai, Z.X., Sun, Z.K. and Siegel, P.B., 2014. Body weight selection affects quantitative genetic correlated responses in gut microbiota. PLOS One, 9: e89862. https://doi.org/10.1371/journal. pone.0089862

Nayak, S.K., 2010. Role of gastrointestinal microbiota in fish. Aquacult. Res., 41: 1553-1573. https://doi. org/10.1111/j.1365-2109.2010.02546.x

Nel, A., Pletschke, B.I., Jones, C.L.W., Kemp, J., Robinson, G. and Britz, P.J., 2017. Effects of kelp Ecklonia maxima inclusion in formulated feed on the growth, feed utilisation and gut microbiota of South African abalone Haliotis midae. Afr. J. mar. Sci., 39: 183-192. https://doi.org/10.2989/181423 2X.2017.1338203

Nord, C.E., 1990. Studies on the ecological impact of antibiotics. Eur. J. clin. Microbiol. Infect. Dis., 9: 517-518. https://doi.org/10.1007/BF01964294

Pérez, T., Balcázar, J.L., Ruizzarzuela, I., Halaihel, N., Vendrell, D., De, B.I. and Múzquiz, J.L., 2010. Hostmicrobiota interactions within the fish intestinal ecosystem. Mucosal Immunol., 3: 355-360. https:// doi.org/10.1038/mi.2010.12

Qiu, L., Song, L., Xu, W., Ni, D. and Yu, Y., 2007. Molecular cloning and expression of a toll receptor gene homologue from zhikong scallop, Chlamys farreri. Fish Shellf. Immunol., 22: 451-466. https:// doi.org/10.1016/j.fsi.2006.05.003

Razin, S., Yogev, D. and Naot, Y., 1998. Molecular 
biology and pathogenicity of mycoplasmas. Microbiol. mol. Biol. Rev., 62: 1094-1156.

Ring, E., Olsen, R.E., Mayhew, T.M. and Myklebust, R., 2003. Electron microscopy of the intestinal microflora of fish. Aquaculture, 227: 395-415. https://doi.org/10.1016/j.aquaculture.2003.05.001

Round, J.L., Mazmanian, S.K. 2009. The gut microbiota shapes intestinal immune responses during health and disease. Nat. Rev. Immunol., 9: 313-323. https:// doi.org/10.1038/nri2515

Rubiolo, J.A., Lozano-Leon, A., Rodriguez-Souto, R., Rodríguez, N.F., Vieytes, M.R. and Botana, L.M., 2018. The impact of depuration on mussel hepatopancreas bacteriome composition and predicted metagenome. Antonie Van Leeuwenhoek, 111: 1117-1129. https://doi.org/10.1007/s10482018-1015-y

Sapkota, A., Sapkota, A.R., Kucharski, M., Burke, J., Mckenzie, S., Walker, P. and Lawrence, R., 2008. Aquaculture practices and potential human health risks: current knowledge and future priorities. Environ. Int., 34: 1215. https://doi.org/10.1016/j. envint.2008.04.009

Sarkozy, G., 2001. Quinolones: A class of antimicrobial agents. Vetmed-czech, 46: 257-274. https://doi. org/10.17221/7883-VETMED

Schloss, P.D., Westcott, S.L., Ryabin, T., Hall, J.R., Hartmann, M., Hollister, E.B., Lesniewski, R.A., Oakley, B.B., Parks, D.H., Robinson, C.J., Sahl, J.W., Stres, B., Thallinger, G.G., Van Horn, D.J. and Weber C.F., 2009. Introducing mothur: open-source, platform-independent, community-supported software for describing and comparing microbial communities. Appl. environ. Microb., 75: 7537. https://doi.org/10.1128/AEM.01541-09

Sekirov, I., Russell, S.L., Antunes, L.C. and Finlay, B.B., 2010. Gut microbiota in health and disease. Physiol. Rev., 90: 859-904. https://doi.org/10.1152/ physrev.00045.2009

Shin, Whon, Woong, T., Bae and JinWoo. 2015. Proteobacteria: microbial signature of dysbiosis in gut microbiota. Trends Biotechnol., 33: 496-503. https://doi.org/10.1016/j.tibtech.2015.06.011

Suez, J., Korem, T., Zeevi, D., Zilbermanschapira, G., Thaiss, C.A., Maza, O., Israeli, D., Zmora, N., Gilad, S., Weinberger, A., Kuperman, Y., Harmelin, A., Kolodkin-Gal, I., Shapiro, H., Halpern, Z., Segal, E. and Elinav, E., 2014. Artificial sweeteners induce glucose intolerance by altering the gut microbiota. Nature, 70: 181-186. https://doi.org/10.1038/ nature 13793

Tanaka, R., Ootsubo, M., Sawabe, T., Ezura, Y. and Tajima, K., 2004. Biodiversity and in situ abundance of gut microflora of abalone (haliotis discus hannai) determined by culture-independent techniques. Aquaculture, 241: 453-463. https://doi. org/10.1016/j.aquaculture.2004.08.032

Trouchon, T. and Lefebvre, S., 2016. A review of enrofloxacin for veterinary use. Open J. Vet. Med., 6: 40-58. https://doi.org/10.4236/ojvm.2016.62006

Turnbaugh, P.J., Hamady, M., Yatsunenko, T., Cantarel, B.L., Duncan, A., Ley, R.E., Sogin, M.L., Jones, W. J., Roe, B.A., Affourtit, J.P., Egholm, M., Henrissat, B., Heath, A.C., Knight, R. and Gordon, J.I., 2009. A core gut microbiome in obese and lean twins. Nature, 457: 480. https://doi.org/10.1038/nature07540

Wang, J.L., Liu, J.Z., Chen, Z.L. and Kuang, Y.B., 2005. Effects of enrofloxacin residues on the functions of soil microbes. Acta Ecol. Sin., 25: 279-282.

Wang, J., Huang, Y., Xu, K., Zhang, X., Sun, H., Fan, L. and Yan, M., 2018. White spot syndrome virus (WSSV) infection impacts intestinal microbiota composition and function in Litopenaeus vannamei. Fish shellf. Immunol., 84: 130-137. https://doi. org/10.1016/j.fsi.2018.09.076

Winters, A.D., Marsh, T.L. and Faisal, M., 2011. Heterogeneity of bacterial communities within the zebra mussel (Dreissena polymorpha) in the laurentian great lakes basin. J. Great Lakes Res., 37: 318-324. https://doi.org/10.1016/j.jglr.2011.01.010

Wong, S., Waldrop, T., Summerfelt, S., Davidson, J., Barrows, F., Kenney, P.B., Welch, T., Wiens, G.D., Snekvik, K., Rawls, J.F. and Good, C., 2013. Aquacultured rainbow trout (oncorhynchus mykiss) possess a largecore intestinal microbiota that is resistant to variation in diet andrearing density. Appl. environ. Microbiol., 79: 4974-4984. https:// doi.org/10.1128/AEM.00924-13

Wu, S., Gao, T., Zheng, Y., Wang, W., Cheng, Y. and Wang, G., 2010. Microbial diversity of intestinal contents and mucus in yellow catfish (Pelteobagrus fulvidraco). Aquaculture, 303: 1-7. https://doi. org/10.1016/j.aquaculture.2009.12.025

Ye, L., Amberg, J., Chapman, D., Gaikowski, M. and Liu, W.T., 2014. Fish gut microbiota analysis differentiates physiology and behavior of invasive asian carp and indigenous american fish. ISME J., 8: 541. https://doi.org/10.1038/ismej.2013.181

Yu, F., Yu, S., Yu, L., Li, Y., Wu, Y., Zhang, H., Qu, L. and Harrington, P.D.B., 2014. Determination of residual enrofloxacin in food samples by a sensitive method of chemiluminescence enzyme immunoassay. Fd. Chem., 149: 71-75. https://doi.org/10.1016/j. foodchem.2013.10.024 
Zhang, M., Sun, Y., Chen, K., Yu, N., Zhou, Z., Chen, L., Du, Z. and Li, E., 2014. Characterization of the intestinal microbiota in pacific white shrimp, Litopenaeus vannamei, fed diets with different lipid sources. Aquaculture, 434: 449-455. https://doi. org/10.1016/j.aquaculture.2014.09.008

Zhang, Y., Wang, X., Hu, M. and Li, P., 2015. Effect of hydraulic retention time (HRT) on the biodegradation of trichloroethylene wastewater and anaerobic bacterial community in the UASB reactor. Appl. Microbiol. Biol., 99: 1977-1987. https://doi. org/10.1007/s00253-014-6096-6

Zheng, H., Liu, H., Zhang, T., Wang, S., Sun, Z., Liu, W. and Li, Y., 2010. Total carotenoid differences in scallop tissues of Chlamys nobilis, (Bivalve: Pectinidae) with regard to gender and shell colour. Fd. Chem., 122: 1164-1167. https://doi. org/10.1016/j.foodchem.2010.03.109 